\title{
A Kinetic and Mechanismic Study of Plasma-Induced Degradation of Monochloropropionic Acids in Water by Means of Anodic Contact Glow Discharge Electrolysis
}

\author{
Haiming Yang, ${ }^{1,2}$ Xiaotong Zhao, ${ }^{1,2}$ Baigang An, ${ }^{1,2}$ Lixiang Li, ${ }^{1,2}$ \\ Shaoyan Wang, ${ }^{1}$ and Maowei $\mathrm{Ju}^{3}$ \\ ${ }^{1}$ School of Chemical Engineering, University of Science and Technology Liaoning, Anshan 114051, China \\ ${ }^{2}$ Institute of Materials Electrochemistry Research, University of Science and Technology Liaoning, \\ 185 Qianshangzhong Road, Anshan 114051, China \\ ${ }^{3}$ National Marine Environmental Monitoring Center, Dalian 116023, China \\ Correspondence should be addressed to Haiming Yang; yanghaiming80@sina.com and Maowei Ju; jumaowei@163.com
}

Received 14 May 2016; Accepted 27 June 2016

Academic Editor: Jiangshui Luo

Copyright @ 2016 Haiming Yang et al. This is an open access article distributed under the Creative Commons Attribution License, which permits unrestricted use, distribution, and reproduction in any medium, provided the original work is properly cited.

\begin{abstract}
Decomposition of aqueous monochloropropionic acids (MCPAs) was investigated by means of anodic contact glow discharge electrolysis (CGDE). With the decay of MCPAs, the corresponding total organic carbon (TOC) also decreased smoothly. Furthermore, it was found that chlorine atoms in the MCPAs were released as chloride ions. As the main by-products, oxalic acid and formic acid were detected. The acetic acid (CA), monochloroacetic acid (MCA), and propanedioic acid (PDA) were also detected as the primary intermediates for decomposition of the corresponding MCPAs. The decay of both MCPAs and TOC obeyed the first-order kinetics, respectively. The apparent rate constant for the decay of MCPAs increased with the increase in $p K_{\mathrm{a}}$ values of MCPAs, while that for the decay of TOC was substantially unaffected. The reaction pathway involving the successive attack of hydroxyl radical and the carbon chain cleavage were discussed based on the products and kinetics.
\end{abstract}

\section{Introduction}

Chlorinated organic compounds (COCs), including chlorinated aromatic compounds (CACs) and chloroalkyl carboxylic acids (CACAs), have been used in polymer materials, herbicides, fungicides, insecticides, and solvents. As a result, COCs were constantly released into the environment [1-3]. Since COCs are toxic, carcinogenic, and persistent, the degradation of COCs compounds is unquestionably important $[4,5]$. In the past decades, the degradation of CACs had been systemically studied by both bioprocesses and advanced oxidation processes (AOPs) [6-13], while, for CACAs, the studies were focusing on chloroacetic acids with two carbon atoms in the carbon chain $[14,15]$. The treatments of monochloroacetic acid (MCA), dichloroacetic acid (DCA), and trichloroacetic acid (TCA) by bioprocesses have been reported $[16,17]$. To exhaustive degradation of chloroacetic acid, AOPs such as photocatalysis has also been employed [18-20]. Recently, the attraction has also been devoted to the other CACAs, which have more carbon atoms in the carbon chain. The decomposition of them has been done by bioprocesses [21, 22]; the decompositions kinetics of 2-MCPA and 3-MCPA have also been investigated [23], while few researches by AOPs have been reported yet [24].

One of the hopeful AOPs, named contact glow discharge electrolysis (CGDE) [25, 26], for exhaustive mineralization of organic pollutants has been developed these years [27-30]. In anodic CGDE, plasma is generated locally in the vicinity of an anode contacting the surface of electrolyte. The ionic species in the plasma are accelerated by the steep potential gradient and rush into the solution. Then, in the reaction zone the energized ionic species break several water molecules into hydrogen and hydroxyl radicals [26, 31]. Hydrogen peroxide is one of the main products of anodic CGDE in the solution of inert electrolytes and it should be formed by the recombination of $\mathrm{OH}$ radicals $[26,31,32]$. 
Based on a series of researches on decomposition of organic pollutants by anodic CGDE, it was assumed that hydroxyl radical would act as the most responsible keyspecies for the destruction of organic pollutants [27-30, 33-38]. Anodic CGDE has also been proved to be one of the hopeful AOPs to mineralize organic pollutants; thus it seems truly opportune to acquire practical knowledge of the aqueous degradation of CACAs induced by anodic CGDE.

Recently, Lei et al. studied the decomposition of trichloroacetic acid (TCA) in water by CGDE [39]; our group reported the degradation of MCA [40]. In the present paper, the comprehensive degradation of two monochloropropionic acids (MCPAs), typical CACAs with three carbon atoms in the carbon chain, by means of anodic CGDE is investigated. The study mainly focused on the cleavage of the carbon chain and kinetic aspects.

\section{Experimental}

The reaction apparatus and assembly for CGDE experiment are illustrated in Figure 1. A H-type glass cell separated with Nafion membrane N117 made by Techno-Sigma Co. (Okayama, Japan) was employed. And the capacity was $180 \mathrm{~mL}$ for each compartment. The anode, from which the discharge was emitted, was a pointed platinum wire $(0.6 \mathrm{~mm}$ in diameter) sealed into a glass tube which was introduced into the cell. The cathode was a stainless steel plate and immersed into $180 \mathrm{~mL}$ of aqueous phosphate solution $(8.7 \mathrm{mmol} / \mathrm{L}$ potassium dihydrogen phosphate and $30.4 \mathrm{mmol} / \mathrm{L}$ disodium hydrogen phosphate, $\mathrm{pH}=7.4$ ). Anode and cathode were separated by Nafion membrane N117, across which the electron still could path through. The voltage of $500 \mathrm{~V}$ from a DC power supply (ELEPOS PS-1510) was applied between both electrodes to start the run. The depth of discharge electrode (anode) dipped into solution was adjusted so that the average current might be $70 \mathrm{~mA}$. The total electricity passing during the electrolysis was monitored with a digital coulomb meter (Hokuto Denko HF-201). In the course of the reaction, the cell was mounted on an icewater bath to maintain the temperature of the bulk solution in the range of $10-20^{\circ} \mathrm{C}$. The solution was gently stirred with a magnet bar covered with Teflon.

Reagent-grade MCPAs were used without further purification. Identities of the products, as well as unreacted starting material, were determined by high-performance liquid chromatography (HPLC; Shimadzu LC10A). For the quantification of MCPAs, MCA, PDA, and CA, a Shodex Ionpak KC-811 column $(8 \mathrm{ID} \times 300 \mathrm{~mm})$ connected to an ultraviolet- (UV-) visible detector (Shimadzu SPD-M10A) was used; the eluent used was $50 \mathrm{~mol} / \mathrm{L}$ perchloric acid. A Shodex Ionpak KC-811 column $(8 \times 300 \mathrm{~mm})$ with an eluent composed of $0.5 \mathrm{mmol} / \mathrm{L}$ and $15 \mathrm{mmol} / \mathrm{L}$ perchloric acid + acetonitrile $(85: 15 \mathrm{~V} / \mathrm{V})$ was used together with a conductivity detector (Shimadzu CDD-6A) for the analysis of formic acid, and a Shodex Ionpak KC-811 column with an eluent composed of $0.5 \mathrm{mmol} / \mathrm{L}$ perchloric acid was used together with a conductivity detector (Shimadzu CDD-6A) for the analysis of oxalic acid. In addition, Shodex Ionpak IC

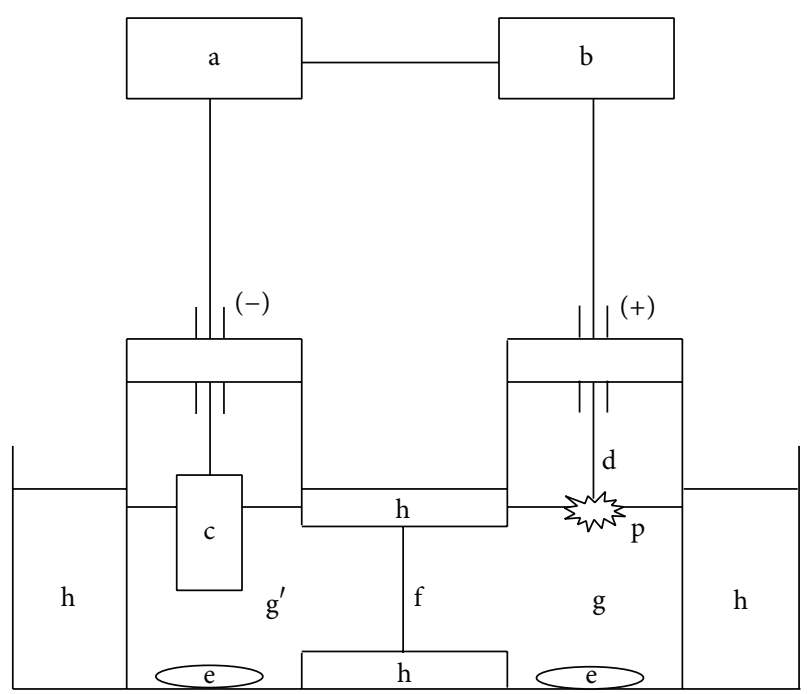

Figure 1: Apparatus for CGDE. a: digital coulomb meter; b: Dc power supply; c: cathode; d: anode; e: Teflon-coated magnet bar; f: Nafion membrane N117; g: electrolytic solution; $\mathrm{g}^{\prime}$ : phosphate buffer solution; h: ice-water bath; p: plasma.

I-524A column with the eluent of $2.5 \mathrm{mmol} / \mathrm{L}$ phthalic acid $\left(\mathrm{pH} 2.5\right.$, flow rate $1.5 \mathrm{~mL} / \mathrm{min}, 40^{\circ} \mathrm{C}$ ) was used together with a conductivity detector for the analysis of chloride ion. The amount of total organic carbon (TOC) in the solution was measured by a TOC analyser (Shimadzu TOC-V $\mathrm{V}_{\mathrm{E}}$ ).

\section{Results and Discussion}

3.1. Decomposition of MCPAs. Two of MCPAs, including 2MCPA and 3-MCPA, were subject to CGDE. Each of them smoothly degraded when CGDE was carried out between the platinum anode and the surface of the solution. With the decay of MCPAs, the amount of total organic carbon (TOC) in water also decreased. It should be noted that the decrease in TOC corresponds to the formation of inorganic carbon (IC). In addition, it was found that chlorine atoms in MCPAs were released as chloride ions.

The outline of decomposition of 3-MCPA, as a typical example, is investigated in detail. In Figure 2, the variations of the concentrations of 3-MCPA, TOC, and chloride ion with the discharge time are displayed, where the initial concentration of 3-MCPA was $5.0 \mathrm{mmol} / \mathrm{L}$, corresponding to the carbon concentration of $180 \mathrm{ppm}$. On starting the reaction, the concentrations of 3-MCPA and TOC decreased monotonously with the discharge time, respectively. After $240 \mathrm{~min}, 76 \%$ of 3 -MCPA was consumed and $44 \%$ of TOC disappeared. This indicates that CGDE can convert carbon atoms in carbon chain of MCPA to IC, which might exist as hydrogen carbonate in the solution or carbon dioxide released to the gas phase. Furthermore, $65 \%$ of chlorine atoms in 3-MCPA were liberated as chloride ions.

The gap between the decay curves of 3-MCPA and TOC indicates the presence of organic intermediate products. In the reaction mixture, a variety of organic substances including some carboxylates were found but most of them 
TABLE 1: Elemental yields of products from CGDE of 3-MCPA ${ }^{\mathrm{a}}$.

\begin{tabular}{|c|c|c|c|c|c|c|c|c|c|c|}
\hline \multirow{2}{*}{ Time (min) } & \multirow{2}{*}{$\begin{array}{c}\text { 3-MCPA } \\
\text { conversion (\%) }\end{array}$} & \multicolumn{3}{|c|}{ Chlorine } & \multicolumn{6}{|c|}{ Carbon } \\
\hline & & $\mathrm{Cl}^{-}$ & MCA & $\mathrm{ND}^{\mathrm{c}}$ & MCA & PDA & Oxalic acid & Formic acid & $\mathrm{IC}^{\mathrm{b}}$ & $\mathrm{ND}^{\mathrm{c}}$ \\
\hline 0 & 0 & 0 & 0 & 0 & 0 & 0 & 0 & 0 & 0 & 0 \\
\hline 30 & 27 & 24 & 0 & 3 & 2 & 5 & 2 & 2 & 7 & 10 \\
\hline 60 & 45 & 42 & 1 & 3 & 3 & 8 & 3 & 3 & 15 & 14 \\
\hline 90 & 55 & 48 & 2 & 4 & 3 & 9 & 4 & 3 & 21 & 14 \\
\hline 120 & 59 & 53 & 3 & 2 & 3 & 10 & 5 & 4 & 27 & 11 \\
\hline 150 & 64 & 57 & 5 & 2 & 4 & 11 & 4 & 4 & 32 & 7 \\
\hline 180 & 68 & 59 & 8 & 1 & 6 & 12 & 3 & 5 & 37 & 5 \\
\hline 210 & 74 & 63 & 10 & 1 & 8 & 13 & 3 & 5 & 40 & 4 \\
\hline 240 & 76 & 65 & 10 & 1 & 8 & 14 & 3 & 6 & 44 & 1 \\
\hline
\end{tabular}

${ }^{\mathrm{a}} \mathrm{C}_{0}: 5.0 \mathrm{mmol} / \mathrm{L} ;{ }^{\mathrm{b}}$ inorganic carbon; ${ }^{\mathrm{c}}$ not determined.

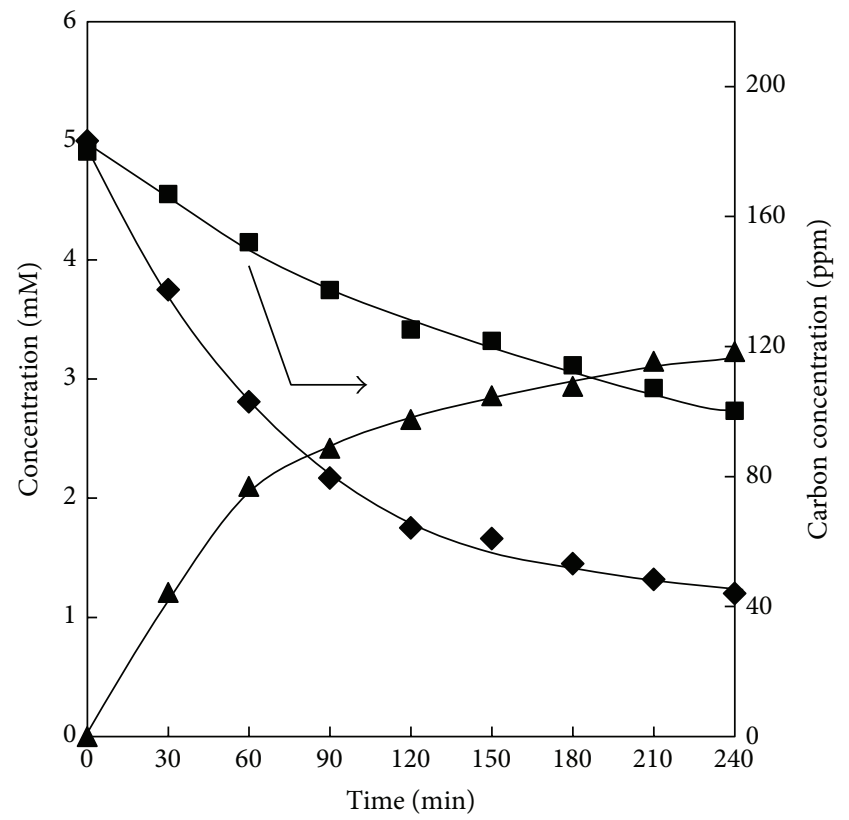

$\boldsymbol{\mathrm { Cl } ^ { - }}$
$3-\mathrm{MCPA}$
TOC

Figure 2: CGDE of 3-MCPA $\left(C_{0}: 5.0 \mathrm{mmol} / \mathrm{L}\right)$.

have not been well determined yet, because of the minuteness and nonavailability. MCA, PDA, oxalic acid, and formic acid were only worth quantifying. In Figure 3, their variations of them with the discharge time were shown. Both PDA and MCA were considered as intermediate products in the early period of the 3-MCPA decompositions, and their concentrations increased for the 210 mins. According to the concentrations, PDA was formed more favorably than MCA, suggesting the degradation path resulting in PDA should be more important than that of MCA. Both formic acid and oxalic acid were intermediate products for the further decomposition of 3-MCPA. The concentration of formic acid was always the highest and increased through the reaction,

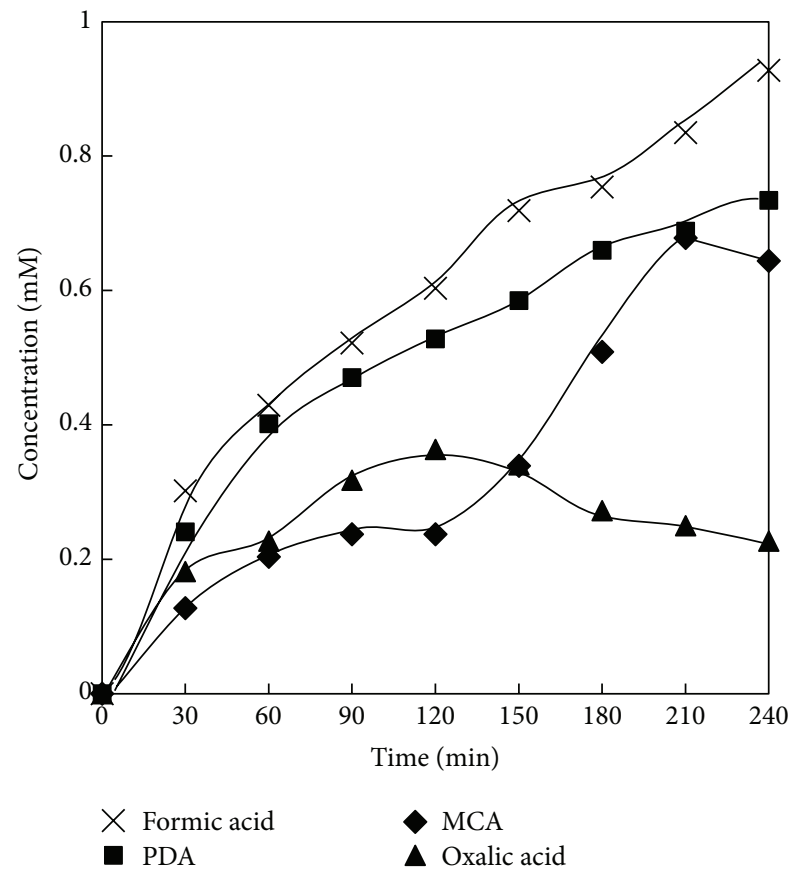

Figure 3: Carboxylates in CGDE of 3-MCPA $\left(C_{0}: 5.0 \mathrm{mmol} / \mathrm{L}\right)$.

while the concentration of oxalic acid culminated at $120 \mathrm{~min}$ and then decreased obviously for the remaining time of the reaction. Formic acid was formed more favorably than oxalic acid, while oxalic acid appeared fairly reactive under the condition. However, it seems improbable that formic acid might result from the decomposition of oxalic acid, since formic acid was not produced in the reaction of oxalic acid as a starting material [35].

The elemental yields of the aforesaid products, namely, IC, PDA, MCA, oxalic acid, formic acid, and $\mathrm{Cl}^{-}$, are tabulated as well as the conversion of 3-MCPA in Table 1 . The yield was defined as the percentage of moles of a certain element (C or $\mathrm{Cl}$ ) in each product per initial moles of that in the starting material. The yields of undetermined intermediates, specified as ND, were estimated so as to balance the sum of yields 
TABLE 2: Elemental yields of products at $240 \mathrm{~min}$ from CGDE of MCPAs ${ }^{\mathrm{a}}$.

\begin{tabular}{lccccccccccc}
\hline \multirow{2}{*}{ MCPA } & \multirow{2}{*}{ Conversion (\%) } & \multicolumn{3}{c}{ Chlorine } & \multicolumn{4}{c}{ Carbon } \\
& & $\mathrm{Cl}^{-}$ & MCA & $\mathrm{ND}^{\mathrm{c}}$ & $\mathrm{MCA}$ & $\mathrm{CA}$ & $\mathrm{PDA}$ & Oxalic acid & Formic acid $^{\mathrm{IC}^{\mathrm{b}}}$ & $\mathrm{ND}^{\mathrm{c}}$ \\
\hline 3-MCPA & 76 & 65 & 10 & 1 & 8 & $*$ & 14 & 3 & 6 & 44 & 1 \\
2-MCPA & 70 & 69 & $*$ & 1 & $*$ & 10 & $*$ & 2 & 3 & 52 \\
\hline
\end{tabular}

${ }^{\mathrm{a}} \mathrm{C}_{0}: 5.0 \mathrm{mmol} / \mathrm{L} ;{ }^{\mathrm{b}}$ inorganic carbon; ${ }^{\mathrm{c}}$ not determined; ${ }^{*}$ the corresponding intermediate products were not detected through the reaction time.

TABLE 3: Primary products in CGDE of MCPAs.

\begin{tabular}{|c|c|c|c|c|}
\hline Starting material & & Prim & & \\
\hline $\begin{array}{l}\mathrm{ClCH}_{2} \mathrm{CH}_{2} \mathrm{COOH} \\
\text { (3-MCPA) }\end{array}$ & $\begin{array}{l}\mathrm{HOOCCOOH} \\
\text { (oxalic acid) }\end{array}$ & $\begin{array}{c}\mathrm{HCOOH} \\
\text { (formic acid) }\end{array}$ & $\begin{array}{c}\mathrm{ClCH}_{2} \mathrm{COOH} \\
\text { (MCA) }\end{array}$ & $\begin{array}{c}\mathrm{HOOCCH} \mathrm{CHOH}_{2} \mathrm{COO} \\
(\mathrm{PDA})\end{array}$ \\
\hline $\begin{array}{l}\mathrm{CH}_{3} \mathrm{CHClCOOH} \\
(2-\mathrm{MCPA})\end{array}$ & $\begin{array}{l}\text { HOOCCOOH } \\
\text { (oxalic acid) }\end{array}$ & $\begin{array}{c}\mathrm{HCOOH} \\
\text { (formic acid) }\end{array}$ & $\begin{array}{c}\mathrm{CH}_{3} \mathrm{COOH} \\
(\mathrm{CA})\end{array}$ & \\
\hline
\end{tabular}

with the conversion. Especially in the earlier stage of run, ND was noticeable, but it steadily lowered as the conversion went up. It could be ascertained that the yields of $\mathrm{Cl}^{-}$ion and IC reached $65 \%$ and $44 \%$, respectively, at the discharge time of $240 \mathrm{~min}$.

The decomposition of the 2-MCPA by means of CGDE was similarly examined. The behavior of the concentrations of starting materials, TOC, and chloride ion was substantially identical to those in the case of the other 2-MCPA. In Table 2, the elemental yields of products in CGDE of the 3-MCPA and 2-MCPA at the discharge time of $240 \mathrm{~min}$ are summarized. It was confirmed that about $70 \sim 76 \%$ of chlorine atoms and about $50 \%$ of carbon atoms could be mineralized by means of CGDE throughout all of MCPAs.

3.2. Products and Decomposition Mechanisms of MCPAs. The information of minor products is also important to elucidate the degradation of MCPAs. Hence, the primary products, which might be formed in the initial stage of decomposition, were searched in the reaction solutions of discharge by using IC, though there were still some intermediate products undetected and undefined due to the intermediate instability and absence of standard samples. The identified products are collected in Table 3.

For all the MCPAs subjected to CGDE, both oxalic acid and formic acid were found as intermediate products. And some other products were also detected. Based on the product survey, the possible formation pathways for the intermediate products were discussed as the following (Schemes 1 and 2).

For the decomposition of 3-MCPA, four intermediates including MCA, PDA, oxalic acid, and formic acid were detected (Table 3 ). The formation of PDA means the substitution reaction of hydrogen atom on $\beta$ carbon by hydroxyl radical should take place during CGDE. Since the concentration of oxalic acid increased through CGDE as shown in Table 1, the substitution reaction of hydrogen atoms on $\alpha$ carbon by hydroxyl radical should also take place; subsequently the carbon bond between $\alpha$ carbon and carboxyl group cleavage would occur resulting in oxalic acid and formic acid (Scheme 1). Finally oxalic acid and formic acid were converted to $\mathrm{IC}$ and $\mathrm{H}_{2} \mathrm{O}$.
The formation of MCA indicted another reaction pathway; that is, the substitution reaction of hydrogen atoms on $\alpha$ carbon by hydroxyl radical should take place; subsequently the carbon chain cleavage between $\alpha$ carbon and carboxyl group would occur resulting in MCA and formic acid. In addition, during the decomposition of MCA by CGDE, oxalic acid was undetected. Comparing the yields of MCA and PDA in Table 1, one can notice that the formation of PDA was easier than the formation of MCA.

For the decomposition of 2-MCPA, three intermediates including CA, oxalic acid, and formic acid were detected (Table 3). The formation of CA indicted the carbon chain cleavage pathway: firstly substitution reaction of hydrogen atoms on $\alpha$ carbon by hydroxyl radical should take place; subsequently the carbon chain cleavage between $\alpha$ carbon and carboxyl group would occur resulting in CA and formic acid (Scheme 2).

As there was no oxalic acid detected in CGDE of CA, for the formation of oxalic acid another reaction pathway was proposed: both the substitution reactions of hydrogen atom on $\alpha$ and $\beta$ carbons should take place at the beginning; finally the carbon bond between $\alpha$ carbon and carboxyl group cleavage would occur resulting in oxalic acid and formic acid (Scheme 3).

For both 3-MCPA and 2-MCPA, in which hydrogen atoms bound at the $\alpha$ carbon, intermediate products such as MCA and CA formed were found. These results might be reasonably explained by the idea that the institution of the atoms bonded to carbon in MCPA by hydroxyl radical would occur at the hydrogen atom bonded with $\alpha$ carbon atom to the carboxyl group in MCPA resulting in the cleavage of the bond between $\alpha$ carbon atom and carboxyl group as shown in Schemes 1 and 2.

Based on the product survey, it can be assumed that degradation of aqueous MCPAs by CGDE proceeds in a successive manner as follows: (1) hydroxylation of MCPAs giving rise to substitution reaction of hydrogen or chlorine atom in the carbon chain, subsequently (2) oxidative carbon chain cleavage leading to the formation of carboxylates that includes oxalic acid and formic acid, and ultimately (3) mineralization to inorganic carbon (IC) and $\mathrm{Cl}^{-}$. 


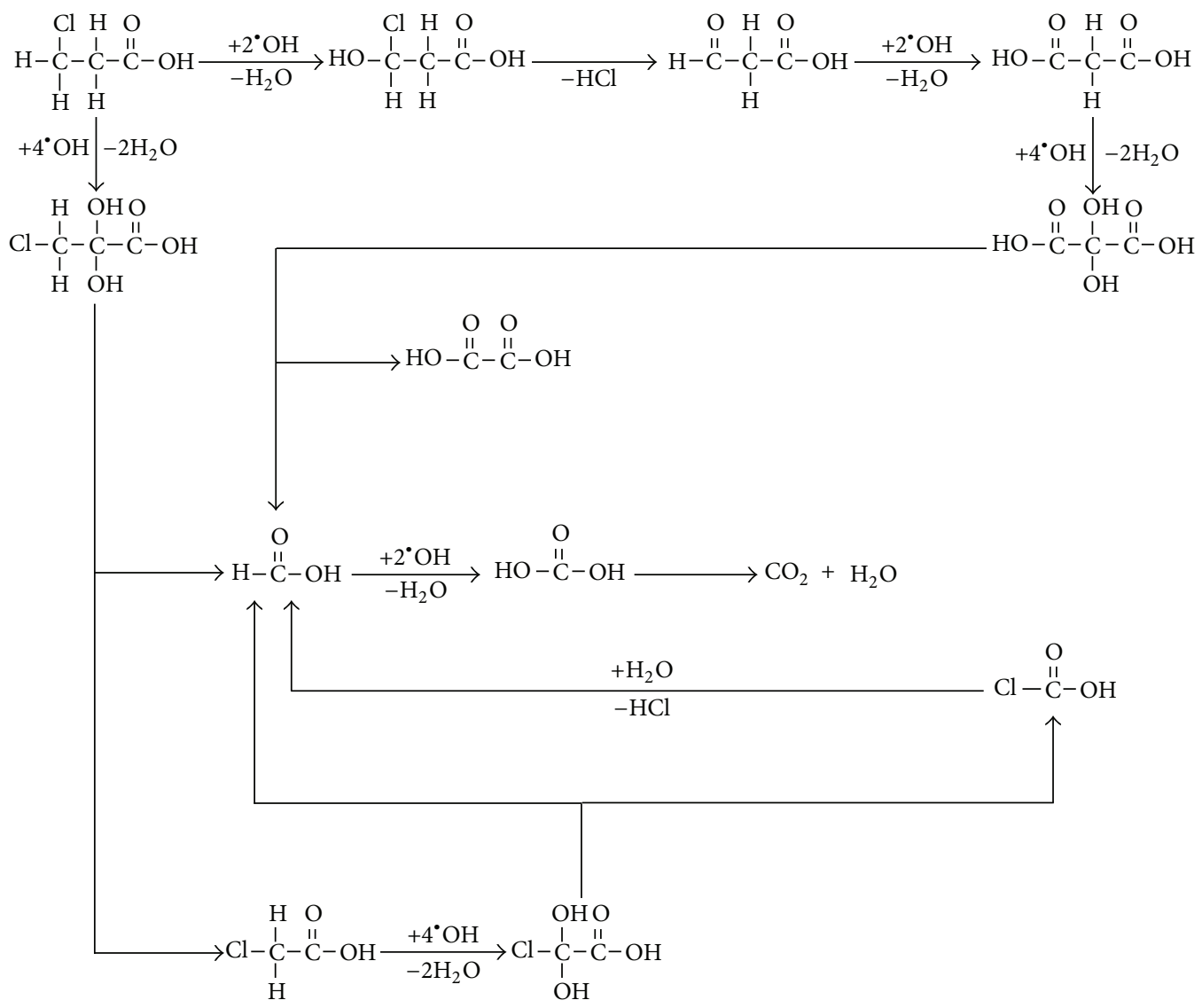

SCheme 1: Possible decomposition pathway for 3-MCPA by CGDE.

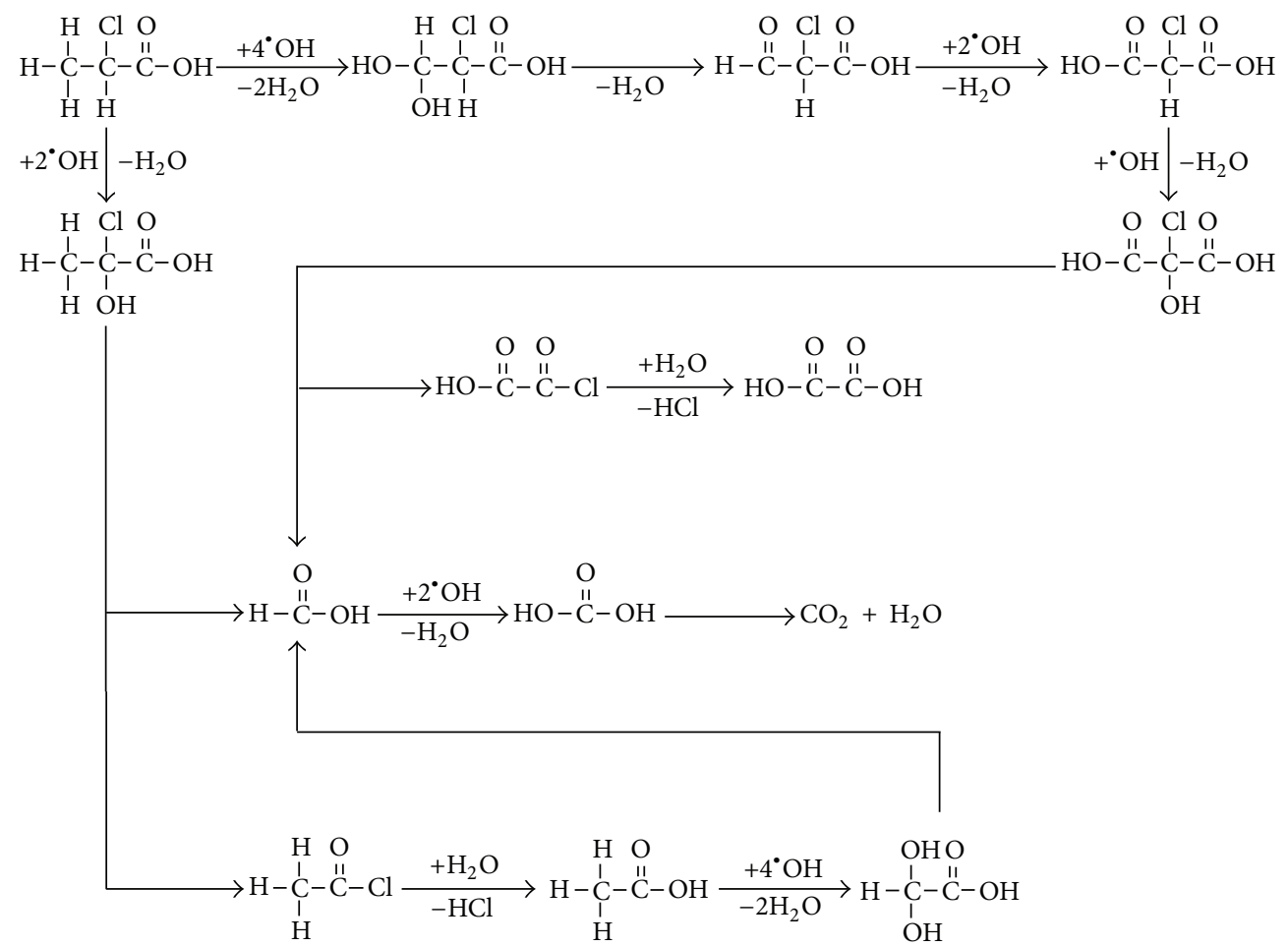

SCHEMe 2: Possible decomposition pathway for 2-MCPA by CGDE. 


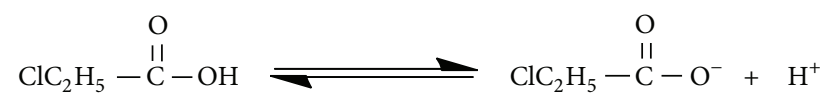

SCHEME 3: Ionization equilibrium for MCPAs.

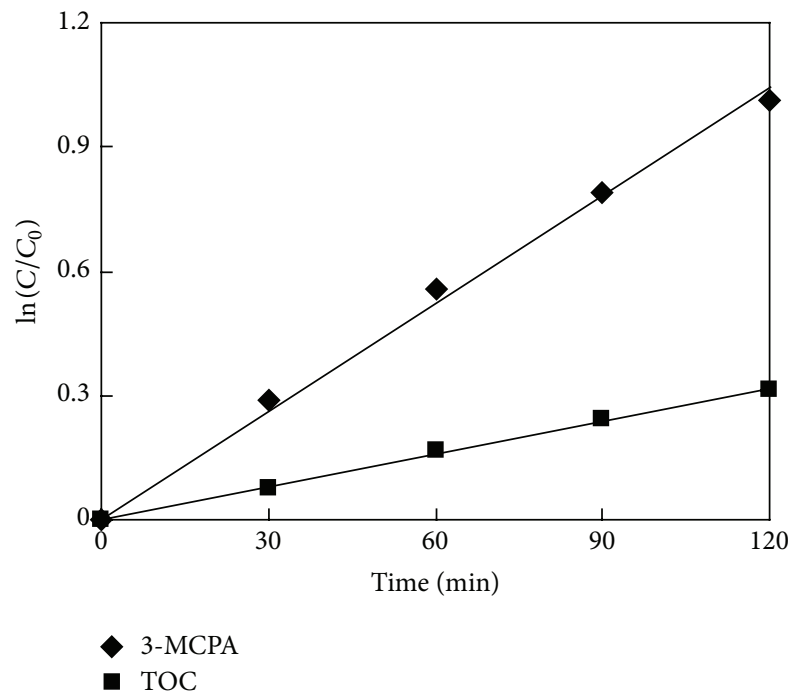

Figure 4: Kinetical plots in CGDE of 3-MCPA $\left(C_{0}: 5.0 \mathrm{mmol} / \mathrm{L}\right)$.

3.3. Kinetics of MCPAs Decomposition. As the decay curves of the stating material and TOC in Figure 2 appeared to be exponential during the reaction, it was attempted to apply the data to the integral rate equation for the first-order reaction as:

$$
\ln \left(\frac{C_{0}}{C}\right)=k t,
$$

where $C, C_{0}, k$, and $t$ denote the concentration of 3-MCPA or TOC at the given reaction time, that is, at $t=0$, the rate constant, and reaction time, respectively.

In consequence, for each set of data concerning the decay, a straight line with good correlation was obtained (Figure 4). This result indicates that both 3-MCPA and TOC were reacted following the first-order kinetics. The apparent rate constants, $k_{3-\mathrm{MCPA}}$ and $k_{\mathrm{TOC}}$, for the decay of 3-MCPA and TOC were calculated from the slope of each line to be $0.89 \times 10^{-2} \mathrm{~min}^{-1}$ and $0.31 \times 10^{-2} \mathrm{~min}^{-1}$, respectively.

In the reactions of 2-MCPA, the exponential curves for the decay of 2-MCPA and TOC were also obtained. Thus, the rate constants for 2-MCPA were determined similarly and are summarized together with the correlation coefficients in Table 4 , where the $p K_{\mathrm{a}}$ data of the MCPAs are inserted. It might be noticed that $k_{\mathrm{MCPA}}$ depended on the $p K_{\mathrm{a}}$; that is, the higher $p K_{\mathrm{a}}$, the bigger $k_{\mathrm{MCPA}}$.

The $p K_{\mathrm{a}}$ value is one of the most fundamental physicochemical properties of acids such as MCPAs and is defined as (2), where $K_{\mathrm{a}}$ is the equilibrium constant for the ionization process of acids:

$$
p K_{\mathrm{a}}=-\log K_{\mathrm{a}} .
$$

The ionization equilibrium for MCPAs is depicted in Scheme 3. Since the $\mathrm{pH}$ values of the reaction solutions are
TABLE 4: Apparent rate constants, $k_{\mathrm{MCPA}}$ and $k_{\mathrm{TOC}}$, for the decay of MCPAs and TOC.

\begin{tabular}{lccccc}
\hline \multirow{2}{*}{ MCPA } & \multirow{3}{*}{$p K_{\mathrm{a}}$} & $k / 10^{-2} \mathrm{~min}^{-1}$ & $R^{2}$ & $k / 10^{-2} \mathrm{~min}^{-1}$ & $R^{2}$ \\
\hline 3-MCPA & 4.00 & 0.89 & 0.995 & 0.31 & 0.996 \\
2-MCPA & 2.83 & 0.72 & 0.996 & 0.32 & 0.996 \\
\hline
\end{tabular}

about 7.4, the ionizations of MCPAs in solution with $p K_{\mathrm{a}}$ value 2.83 to 4.00 are complete. The $p K_{\mathrm{a}}$ values are affected by the chlorine atom positions on the carbon chain of MCPAs: when the chlorine atom was far from the carboxyl group the value of $p K_{\mathrm{a}}$ was bigger. In the case above, the bigger $p K_{\mathrm{a}}$ was, the more electron pairs that the hydrogen atom connected to the carbon would share are. That means the electrophilic attack of hydroxyl radical at these positions resulting in substitution of hydrogen atom would be easier, and the decomposition rate of MCPAs, $k_{\mathrm{MCPA}}$, was bigger for MCPAs with bigger $p K_{\mathrm{a}}$. On the other hand, $k_{\mathrm{TOC}}$ was irrespective of $p K_{\mathrm{a}}$. This seems reasonable because the rate of final oxidation to inorganic carbon would be supposed to be no more influenced by the characteristics of starting materials such as $p K_{\mathrm{a}}$.

\section{Conclusions}

Each of the two MCPAs subject to CGDE was destructed and eventually converted to inorganic carbon. Most of the chlorines in the MCPAs were liberated as chloride ions. In the initial stage, the attack of hydroxyl radical occurred most favorably at the bond between carbon atom and hydrogen atom resulting in institution of hydrogen atom, to some extent, at the bond between carbon atom and chlorine atom resulting in institution of chlorine atom, but never at the bond between carbon and oxygen atom. The consumption of both MCPAs and TOC obeyed the first-order kinetics. The rate constant for the decay of MCPAs, $k_{\mathrm{MCPA}}$, increased with the increase in $p K_{\mathrm{a}}$, while that for the decay of TOC was irrespective of $p K_{\mathrm{a}}$. This discrepancy could be rationalized by the decomposition pathway, where MCPAs might cascade through the sequence of hydrogen institution by hydroxyl radical giving rise to the chlorohydroxypropionic acid, subsequent formation of corresponding dicarboxylic acid and/or oxidative chain cleavage leading to the formation of carboxylates, and finally mineralization to inorganic carbon (IC) and $\mathrm{Cl}^{-}$.

\section{Competing Interests}

The authors declare that they have no competing interests.

\section{Acknowledgments}

This work was supported by the National Natural Science Foundation of China (Grant no. 51308276), Scientific Research Foundation for Doctors of Liaoning Province (Grant no. 20141123), Growth Plan for Distinguished Young Scholars in Colleges and Universities of Liaoning Province 
China (LJQ2015055), Anshan Science and Technology Program Project (Grant no. 2961), the National Natural Science Foundation of China (51102126), Innovative Research Team in Colleges and Universities of Liaoning Province China (LT2014007), and Natural Science Foundation of Liaoning Province, China (2015020634). Special thanks go to Professor Meguru Tezuka for his comments and support of this work.

\section{References}

[1] A. Khaleel and M. Nawaz, "Enhanced catalytic complete oxidation of 1,2-dichloroethane over mesoporous transition metaldoped $\gamma-\mathrm{Al}_{2} \mathrm{O}_{3}$," Journal of Environmental Sciences, vol. 29, pp. 199-209, 2015.

[2] B. Huang, C. Lei, C. Wei, and G. Zeng, "Chlorinated volatile organic compounds (Cl-VOCs) in environment-sources, potential human health impacts, and current remediation technologies," Environment International, vol. 71, pp. 118-138, 2014.

[3] L. Breitstein, A. Forrest, and R. L. Frew, "Groundwater recovery and treatment for chlorinated organic compounds," Journal of Hazardous Materials, vol. 29, no. 1, pp. 43-58, 1991.

[4] M. Magureanu, N. B. Mandache, and V. I. Parvulescu, "Chlorinated organic compounds decomposition in a dielectric barrier discharge," Plasma Chemistry and Plasma Processing, vol. 27, no. 6, pp. 679-690, 2007.

[5] J. Zhang, G.-B. Li, and J. Ma, "Effects of chlorine content and position of chlorinated phenols on their oxidation kinetics by potassium permanganate," Journal of Environmental Sciences, vol. 15, no. 3, pp. 342-345, 2003.

[6] S. H. Lee, S. H. Lee, S. J. Ryu, C. S. Kang, Y. Suma, and H. S. Kim, "Effective biochemical decomposition of chlorinated aromatic hydrocarbons with a biocatalyst immobilized on a natural enzyme support," Bioresource Technology, vol. 141, pp. 89-96, 2013.

[7] Y. Y. Zhang, K. N. McPhedran, and M. Gamal El-Din, "Pseudomonads biodegradation of aromatic compounds in oil sands process-affected water," Science of the Total Environment, vol. 521-522, pp. 59-67, 2015.

[8] H.-X. Lan, Y.-C. Chen, Z.-H. Chen, and R. Chen, "Cultivation and characters of aerobic granules for pentachlorophenol (PCP) degradation under microaerobic condition," Journal of Environmental Sciences, vol. 17, no. 3, pp. 506-510, 2005.

[9] M. Munoz, Z. M. de Pedro, J. A. Casas, and J. J. Rodriguez, "Assessment of the generation of chlorinated byproducts upon Fenton-like oxidation of chlorophenols at different conditions," Journal of Hazardous Materials, vol. 190, no. 1-3, pp. 993-1000, 2011.

[10] F. Duan, Y. Yang, Y. Li, H. Cao, Y. Wang, and Y. Zhang, "Heterogeneous Fenton-like degradation of 4-chlorophenol using iron/ordered mesoporous carbon catalyst," Journal of Environmental Sciences, vol. 26, no. 5, pp. 1171-1179, 2014.

[11] M. Pera-Titus, V. García-Molina, M. A. Baños, J. Giménez, and S. Esplugas, "Degradation of chlorophenols by means of advanced oxidation processes: a general review," Applied Catalysis B: Environmental, vol. 47, no. 4, pp. 219-256, 2004.

[12] M. Vallejo, M. Fresnedo San Román, I. Ortiz, and A. Irabien, "Overview of the PCDD/Fs degradation potential and formation risk in the application of advanced oxidation processes (AOPs) to wastewater treatment," Chemosphere, vol. 118, no. 1, pp. 44-56, 2015.
[13] J. Xue and J. Wang, "Radiolysis of pentachlorophenol (PCP) in aqueous solution by gamma radiation," Journal of Environmental Sciences, vol. 20, no. 10, pp. 1153-1157, 2008.

[14] K.-H. Van Pée and S. Unversucht, "Biological dehalogenation and halogenation reactions," Chemosphere, vol. 52, no. 2, pp. 299-312, 2003.

[15] R. A. Bailey, H. M. Clark, J. P. Ferris, S. Krause, and R. L. Strong, "Water systems and water treatment," in Chemistry of the Environment, chapter 11, pp. 415-442, 2nd edition, 2002.

[16] C. Egli, M. Thüer, D. Suter, A. M. Cook, and T. Leisinger, "Monochloro- and dichloroacetic acids as carbon and energy sources for a stable, methanogenic mixed culture," Archives of Microbiology, vol. 152, no. 3, pp. 218-223, 1989.

[17] P. Yu and T. Welander, "Growth of an aerobic bacterium with trichloroacetic acid as the sole source of energy and carbon," Applied Microbiology and Biotechnology, vol. 42, no. 5, pp. 769774, 1995.

[18] P. Kopf, E. Gilbert, and S. H. Eberle, " $\mathrm{TiO}_{2}$ photocatalytic oxidation of monochloroacetic acid and pyridine: influence of ozone," Journal of Photochemistry and Photobiology A: Chemistry, vol. 136, no. 3, pp. 163-168, 2000.

[19] D. W. Bahnemann, S. N. Kholuiskaya, R. Dillert, A. I. Kulak, and A. I. Kokorin, "Photodestruction of dichloroacetic acid catalyzed by nano-sized $\mathrm{TiO}_{2}$ particles," Applied Catalysis B: Environmental, vol. 36, no. 2, pp. 161-169, 2002.

[20] S. Kim and W. Choi, "Dual photocatalytic pathways of trichloroacetate degradation on $\mathrm{TiO}_{2}$ : effects of nanosized platinum deposits on kinetics and mechanism," Journal of Physical Chemistry B, vol. 106, no. 51, pp. 13311-13317, 2002.

[21] G. Chuchani, I. Martin, A. Rotinov, R. M. Dominguez, and P. I. Milagros, "Several mechanisms in the elimination kinetics of $\omega$-chlorocarboxylic acids in the gas phase," Journal of Physical Organic Chemistry, vol. 8, pp. 133-138, 1995.

[22] S. Mesri, R. A. Wahab, and F. Huyop, "Degradation of 3chloropropionic acid (3CP) by Pseudomonas sp. B6P isolated from a rice paddy field," Annals of Microbiology, vol. 59, no. 3, pp. 447-451, 2009.

[23] G. Chuchani, A. Rotinov, and R. M. Dominguez, "The kinetics and mechanisms of gas phase elimination of primary, secondary, and tertiary 2-hydroxyalkylbenzenes," International Journal of Chemical Kinetics, vol. 31, no. 6, pp. 401-407, 1999.

[24] K. K. Ngim and D. G. Crosby, "Photoreduction of the chloropropionic acid of carfentrazone-ethyl in sodium sulfide crane flat meadow solutions," Environmental Toxicology and Chemistry, vol. 21, no. 10, pp. 2007-2013, 2002.

[25] M. A. Malik, "Water purification by plasmas: which reactors are most energy efficient?" Plasma Chemistry and Plasma Processing, vol. 30, no. 1, pp. 21-31, 2010.

[26] A. Hickling and M. D. Ingram, "Contact glow-discharge electrolysis," Transactions of the Faraday Society, vol. 60, pp. 783793, 1964.

[27] S. Tomizawa and M. Tezuka, "Kinetics and mechanism of the organic degradation in aqueous solution irradiated with gaseous plasma," Plasma Chemistry and Plasma Processing, vol. 27, no. 4, pp. 486-495, 2007.

[28] J. Z. Gao, Y. J. Liu, W. Yang, L. M. Pu, J. Yu, and Q. F. $\mathrm{Lu}$, "Oxidative degradation of phenol in aqueous electrolyte induced by plasma from a direct glow discharge," Plasma Sources Science and Technology, vol. 12, no. 4, pp. 533-538, 2003.

[29] L. Wang and X. Jiang, "Plasma-induced reduction of chromium(VI) in an aqueous solution," Environmental Science and Technology, vol. 42, no. 22, pp. 8492-8497, 2008. 
[30] Y. J. Liu and X. Z. Jiang, "Phenol degradation by a nonpulsed diaphragm glow discharge in an aqueous solution," Environmental Science and Technology, vol. 39, no. 21, pp. 8512-8517, 2005.

[31] S. K. Sengupta, R. Singh, and A. K. Srivastava, "A study on nonfaradaic yields of anodic contact glow discharge electrolysis using cerous ion as the $\mathrm{OH}$. scavenger: an estimate of the primary yield of $\mathrm{OH} \cdot$ radicals," Indian Journal of Chemistry, vol. 37, no. 6, pp. 558-560, 1998.

[32] U. Gangal, M. Srivastava, and S. K. Sengupta, "Scavenging effects of aliphatic alcohols and acetone on $\mathrm{H}$ - radicals in anodic contact glow discharge electrolysis: determination of the primary yield," Plasma Chemistry and Plasma Processing, vol. 30, no. 2, pp. 299-309, 2010.

[33] H. Yang, Y. Matsumoto, and M. Tezuka, "Exhaustive breakdown of aqueous monochlorophenols by contact glow discharge electrolysis," Journal of Environmental Sciences, vol. 21, no. 1, pp. S142-S145, 2009.

[34] H. M. Yang and M. Tezuka, "Mineralization of aqueous pentachlorophenolate by anodic contact glow discharge electrolysis," Journal of Environmental Sciences, vol. 23, no. 6, pp. 10441049, 2011.

[35] H. Yang and M. Tezuka, "Plasma-induced complete destruction of tetrachlorophenols in an aqueous solution," Journal of Physics D: Applied Physics, vol. 44, no. 15, Article ID 155203, 2011.

[36] H. M. Yang, B. G. An, S. Y. Wang, L. Li, W. Jin, and L. $\mathrm{Li}$, "Destruction of 4-phenolsulfonic acid in water by anodic contact glow discharge electrolysis," Journal of Environmental Sciences, vol. 25, no. 6, pp. 1063-1070, 2013.

[37] H. Yang, G. Mengen, Y. Matsumoto, and M. Tezuka, "Degradation of monofluorophenols in water irradiated with gaseous plasma," Journal of Environmental Sciences, vol. 25, no. 1, pp. S180-S185, 2013.

[38] H. Yang, Caixia, and M. Tezuka, "Plasma-induced decomposition of dichlorophenols and trichlorophenols in water by means of anodic contact glow discharge electrolysis," Plasma Chemistry and Plasma Processing, vol. 33, no. 6, pp. 1043-1052, 2013.

[39] W. Lei, Z. Huifen, and Y. Xin, "Dechlorination and decomposition of trichloroacetic acid by glow discharge plasma in aqueous solution," Electrochimica Acta, vol. 115, pp. 332-336, 2014.

[40] H. Yang, X. Zhao, B. An et al., "Degradation of monochloroacetic acid by anodic contact glow discharge electrolysis," International Journal of Plasma Environmental Science and Technology, vol. 8, no. 2, pp. 109-112, 2014. 

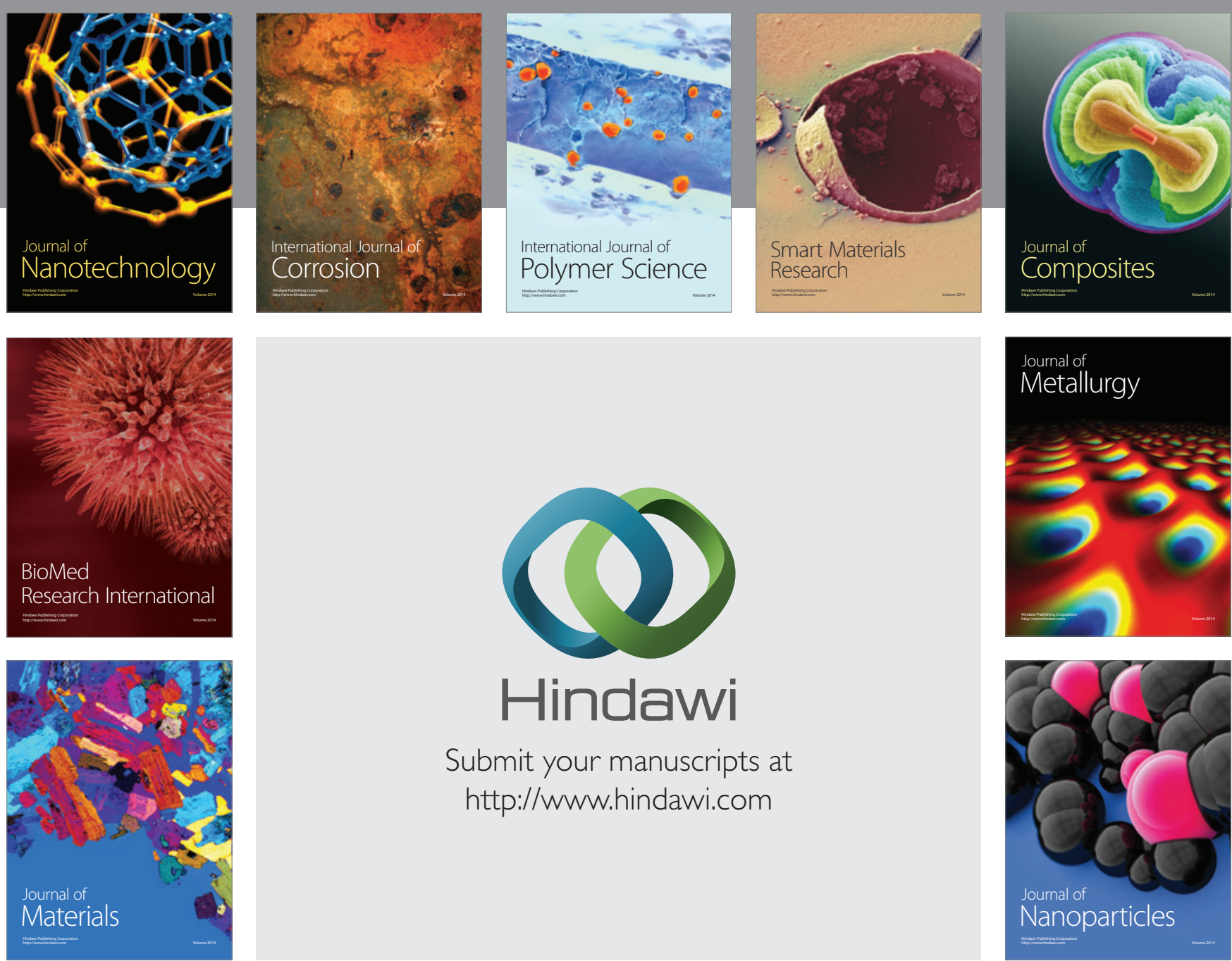

\section{Hindawi}

Submit your manuscripts at

http://www.hindawi.com

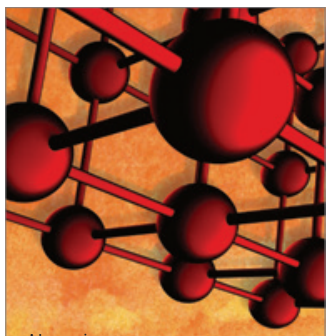

Materials Science and Engineering
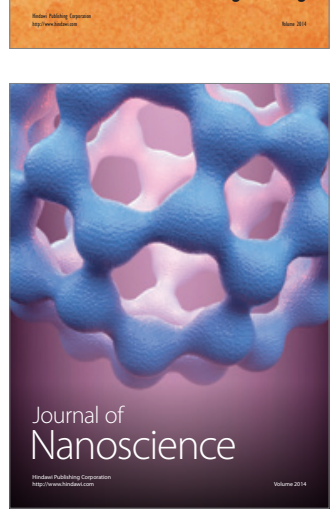
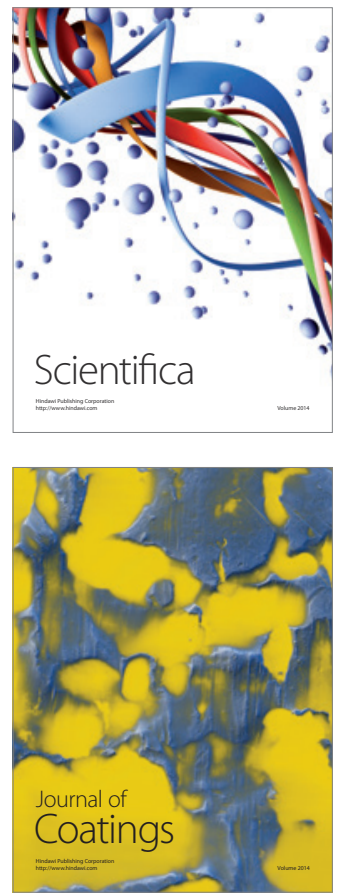
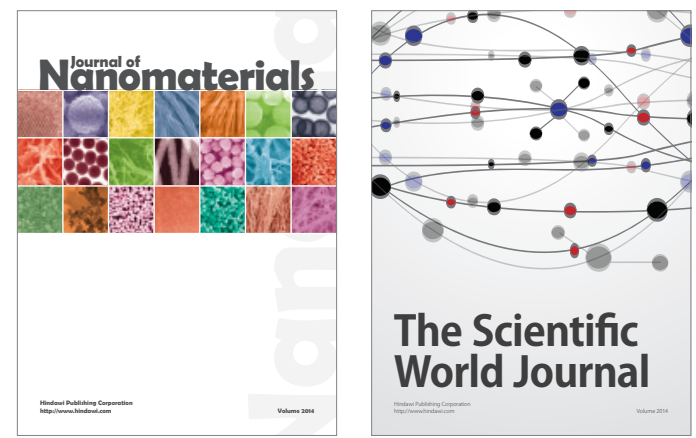

The Scientific World Journal
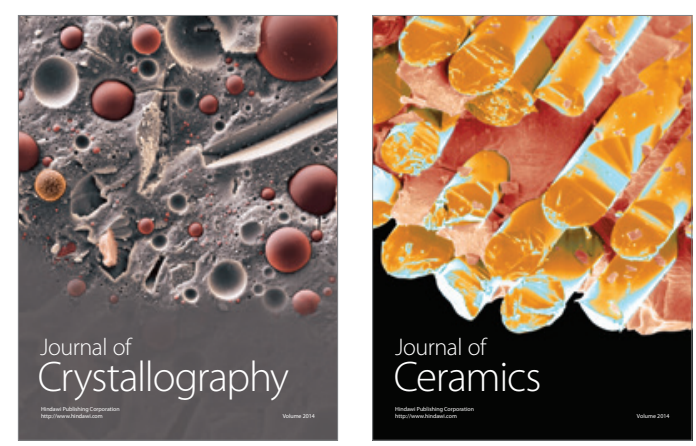
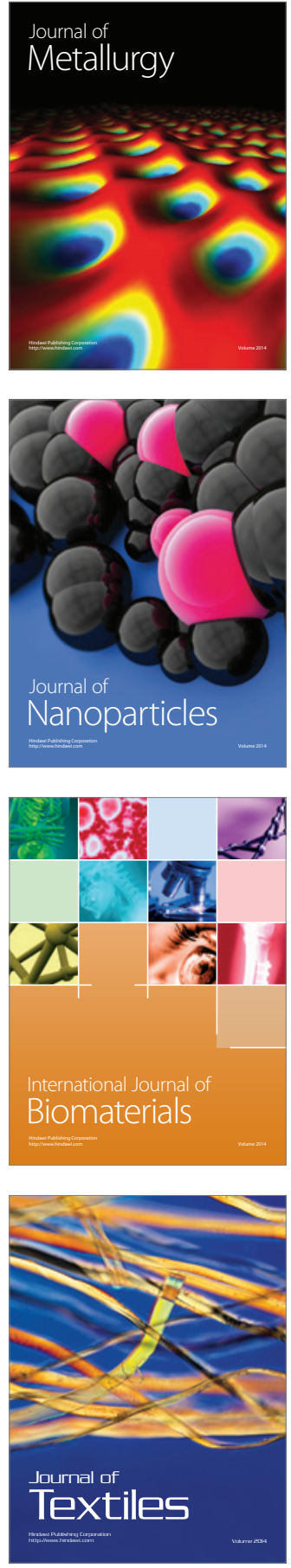